\title{
Lutzomyia derelicta (Diptera: Psychodidae) a Singular New Phlebotomine Sand Fly from an Inselberg in Northeastern Amazonia
}

\author{
Rui A Freitas, Toby V Barrett ${ }^{+}$ \\ Coordenação de Pesquisas em Ciências da Saúde, Instituto Nacional de Pesquisas da Amazônia, \\ Caixa Postal 478, 69011-970 Manaus, AM, Brasil
}

Lutzomyia derelicta $n$. sp. is described from specimens collected in an isolated xeric habitat in the rainforest in the north of the State of Pará, Brazil. The new species lacks the posterior bulge in the dorsal wall of the cibarium characteristic of the New World genus Lutzomyia, and the armature of the male genitalia is of the pattern found elsewhere only in the Old World species of Sergentomyia. L. derelicta is phenetically intermediate between the known species of Lutzomyia and Sergentomyia, and cannot readily be placed in any existing subgenus or species group of either genus.

Key words: Phlebotominae - new species - biogeography - Amazônia

Although the phlebotomine genera Phlebotomus, Sergentomyia and Lutzomyia are inadequately defined (Ashford 1991) in practice most of the included species can be assigned to characteristic subgenera or species-groups, and the generic attribution of a new species is usually not a problem. Furthermore, the currently standard system of classification is based on the premise that "There is little doubt that the species of the Old and New World are not closely related..... Differences for use in keys are unnecessary in pratice" (Lewis et al. 1977). In this paper we describe a new American phlebotomine whose morphological affinites call this premise into question.

\section{MATERIALS AND METHODS}

Type locality - Serra do Cachorro forms part of a narrow band of Paleozoic marine deposits at the southern margin of the Guyana shield, and has probably been dry land since the Permian (Loczy 1966). It is a residual mesa arising abruptly from the lowland rainforest near the right bank of the lower Rio Cachorro or Imabu, a tributary of the Rio Trombetas in the north of the State of Pará. The plateau is covered by vegetation similar to that of the lower slopes and surrounding forest,

\footnotetext{
Work supported by Inpa-PPI and the Pilot Programme for Protection of Brazilian Rainforests/MCT-Subprograma C\&T/PPD G-7.

${ }^{+}$Corresponding author. Fax: +55-92-643.3061. E-mail: tbarrett@inpa.gov.br

Received 8 April 1999

Accepted 7 June 1999
}

but its northern edge ends in an overhanging escarpment, the base of which is permanently sheltered from rain and dripwater. This cliff consists of a silty sericitic sandstone with patches of hematite and mineral clays, a type of sediment rare for the region (Pereira \& Martinelli 1982). There is little vegetation in the sheltered area apart from the saxicolous bromeliad Pitcairnia crinita Pereira and Matinelli, for which this is the type (and only known) locality. The new species was abundant in samples of Psychodidae collected in CDC miniature light traps at the base of the escarpment, but was absent in samples from the plateau or the lower slopes.

Taxonomy - Names of phlebotomine genera and subgenera are used in the sense of Young and Duncan (1994) and Rispail and Léger (1998b). Measurements are mean values in $\mathrm{mm}$ with range in parentheses for 25 male and 21 female specimens cleared in $\mathrm{NaOH}$ and phenol and slide mounted in Canada balsam. Hairs on the abdominal tergites were examined on an uncleared male specimen in alcohol, identified by the genitalia. $L u$. evangelistai specimens used for examination of the interocular suture are from Vila Pitinga, State of Amazonas, approximately $240 \mathrm{~km} \mathrm{~N}$ of the city of Manaus.

\section{TAXONOMIC DESCRIPTION}

Diagnosis - Phlebotominae Kertesz, Phlebotominae sensu Williams 1993. Wings slender. Posterior bulge in dorsal wall of cibarium lacking. Hairs on abdominal tergites 2-6 erect as on 1, not scale-like. First antennal flagellomere with a pair of simple ascoids in both sexes. Postspiracular and lower mesanepisternal setae present, reduced in 
number. A single horizontal row of posterior cibarial teeth present in female. Interocular suture complete. Genital pump simple, lacking associated rods. Attributable to Sergentomyia França for gonostylus of male with four major spines and an acessory median seta, combined with absence of the cibarial bulge in female. Attributed to Lutzomyia França for paired ascoids on antennae of male, erect hairs on abdominal tergites 2-6 and presence of two groups of mesanepisternal setae.

Lutzomyia derelicta, $\mathrm{n}$. sp.

(Figs 1-10)

Male: wing length 1.51(1.43-1.56), width $0.42(0.40-0.45)$. Length of insect 1.9. General colour pale brown, head and genitalia darker, mesonotum only slightly darker than pale pleura and coxae. Head height from vertex to tip of clypeus $0.30(0.29-0.31)$, width $0.28(0.28-0.29)$. Eyes separated by 0.93 equivalent to 7.4 facet diameters. Interantennal suture attaining postfrontal sutures. Flagellomere I 0.19(0.19-0.21) long, II+III $0.19(0.19-0.20)$. Ascoids simple, not attaining apex of flagellomere, one pair visible on all flagellomeres except the apical one. Labrum $0.17(0.15-0.17)$ long. Length of palpomeres: 1 , $0.04 ; 2,0.08(0.07-0.08) ; 3,0.11(0.11-0.12) ; 4$, $0.13(0.11-0.13) ; 5,0.27(0.25-0.29)$. Cibarium unarmed; pigment patch ill-defined, perceptible as a slender, irregular line; arch complete, sometimes poorly defined medially. Pharynx $0.12(0.12-0.13)$ long, unarmed, finely striated transversally in posterior third. Thorax 0.41(0.39-0.44) from anterior margin of mesonotum to tip of scutellum. Pleura with 6 (4-7) small episternal setae, of which 2(1$3)$ upper and 4(3-5) lower. Length of wing-vein sections: alpha $0.26(0.20-0.29)$, beta $0.16(0.13$ 0.19 ), gamma $0.24(0.21-0.28)$, delta 0.04 (minus 0.01 -plus 0.06$)$. Femora without spines. Length of femora, tibiae and basitarsi: foreleg 0.53(0.50$0.57), 0.65(0.60-.071), 0.36(0.33-0.38)$; midleg $0.56(0.51-0.60), 0.77(0.69-0.81), 0.44(0.40-0.47)$; hindleg $0.64(0.59-0.66), \quad 0.90(0.83-0.97)$, $0.50(0.46-0.54)$. Erect-hair sockets on abdominal tergites 2-6 same size as those on 1. Genitalia: style 0.088 long, 0.025 wide, with an inner median seta and four major spines, the proximal ones inserted at 0.75 and 0.85 of the segment and the distal forming an unequal terminal pair; no subterminal seta. Coxite $0.22(0.21-0.22)$ long, 0.04 wide with scattered semideciduous setae on the inner face of the distal half. Paramere simple, apex rounded, distal half covered with short fine setae. Aedeagus slender with acute tip, well sclerotized. Genital pump 0.11 long, each filament 0.39 long or 3.5(3.3-3.6) $\mathrm{x}$ length of pump; filaments slender with acute tips. Surstyle $0.19(0.18-0.19)$ long, not greatly inflated.
Female: wing length $1.65(1.60-1.73)$, width $0.50(0.48-0.55)$. Length of insect 2.0. Colouration as in male. Head height $0.33(0.32-0.35)$, width $0.31(0.29-0.33)$. Eyes separated by $0.12(0.11-0.12)$ equivalent to 7.8 facet diameters. Interantennal suture attaining postfrontal sutures. Flagellomere I $0.19(0.18-0.20)$ long, II+III $0.17(0.16-0.18)$; ascoids present on flagellomeres I-XIII. Labrum $0.20(0.20-0.21)$ long. Length of palpomeres: 1 , $0.04(0.04-0.05) ; 2,0.09(0.08-0.09) ; 3,0.13(0.12-$ $0.13) ; 4,0.13(0.13-0.14) ; 5,0.29(0.28-0.32)$. Newstead's organ inserted submedially on palpomere 3 only (i.e., at level of tip of labrum). Cibarium with a row of 4 translucent horizontal teeth, and an irregular group of small vertical teeth flanked on each side by numerous plate-like anterolateral teeth inserted obliquely; dorsal bulge of posterior wall of structure lacking; pigment patch slender and ill-defined; arch complete. Pharynx $0.14(0.14-0.15)$ long, unarmed. Thorax 0.47(0.44$0.49)$ long. Pleura with 7 (6-9) small episternal setae, of which 2(1-3) upper and 5(4-6) lower. Length of wing-vein sections: alpha $0.32(0.29$ $0.36)$, beta $0.20(0.16-0.21)$, gamma $0.29(0.26-$ $0.31)$, delta 0.08(0.04-0.10). Femora without spines. Length of femora, tibiae and basitarsi: foreleg 0.58(0.57-0.63), 0.64(0.62-.068), 0.36(0.34$0.38)$; midleg 0.62(0.59-0.68), 0.81(0.77-0.83), 0.46(0.43-0.49); hindleg 0.71(0.68-0.78), $0.97(0.94-1.06), 0.53(0.51-0.56)$. Erect-hair sockets on abdominal tergites 2-6 same size as those on 1. Genitalia: spermathecae 0.027(0.024-0.027) long, 0.012 wide, sac-like, irregularly segmented; terminal knob rounded, half as wide as spermatheca; individual sperm ducts smooth and slender, 0.114 long, 0.003 wide; common duct smooth, uniform, 0.057 long, 0.006 wide. Stem of genital fork long (0.105) slender and enlarged at apex.

Type data - Holotype male: Brazil, Pará, município Oriximiná, Serra do Cachorro, $2 \mathrm{~km}$ south of $00^{\circ} 59^{\prime} 43^{\prime \prime} \mathrm{S}$ and $057^{\circ} 07^{\prime} 09^{\prime \prime} \mathrm{W}$ on the Rio Cachorro, base of escarpment approx. $250 \mathrm{~m}$ a.s.l., 21/5/98, light-trap (TV Barrett, F Lima Santos, RG Queiroz). Allotype and 24 male and 20 female paratypes: same data. Holotype, allotype and paratypes in collection of the Instituto Nacional de Pesquisas da Amazônia; other paratypes to be deposited in the Fiocruz collection at the Centro de Pesquisas René Rachou, Belo Horizonte, Brazil.

Etymology: the specific name meaning forsaken or marooned reflects our view of the situation of the topotypical population: cut off by the Cretaceous Atlantic Ocean and subsequently isolated by the surrounding rainforest.

\section{DISCUSSION}

Theodor (1965) regarded the presence of a posterior bulge in the dorsal wall of the cibarium as a 


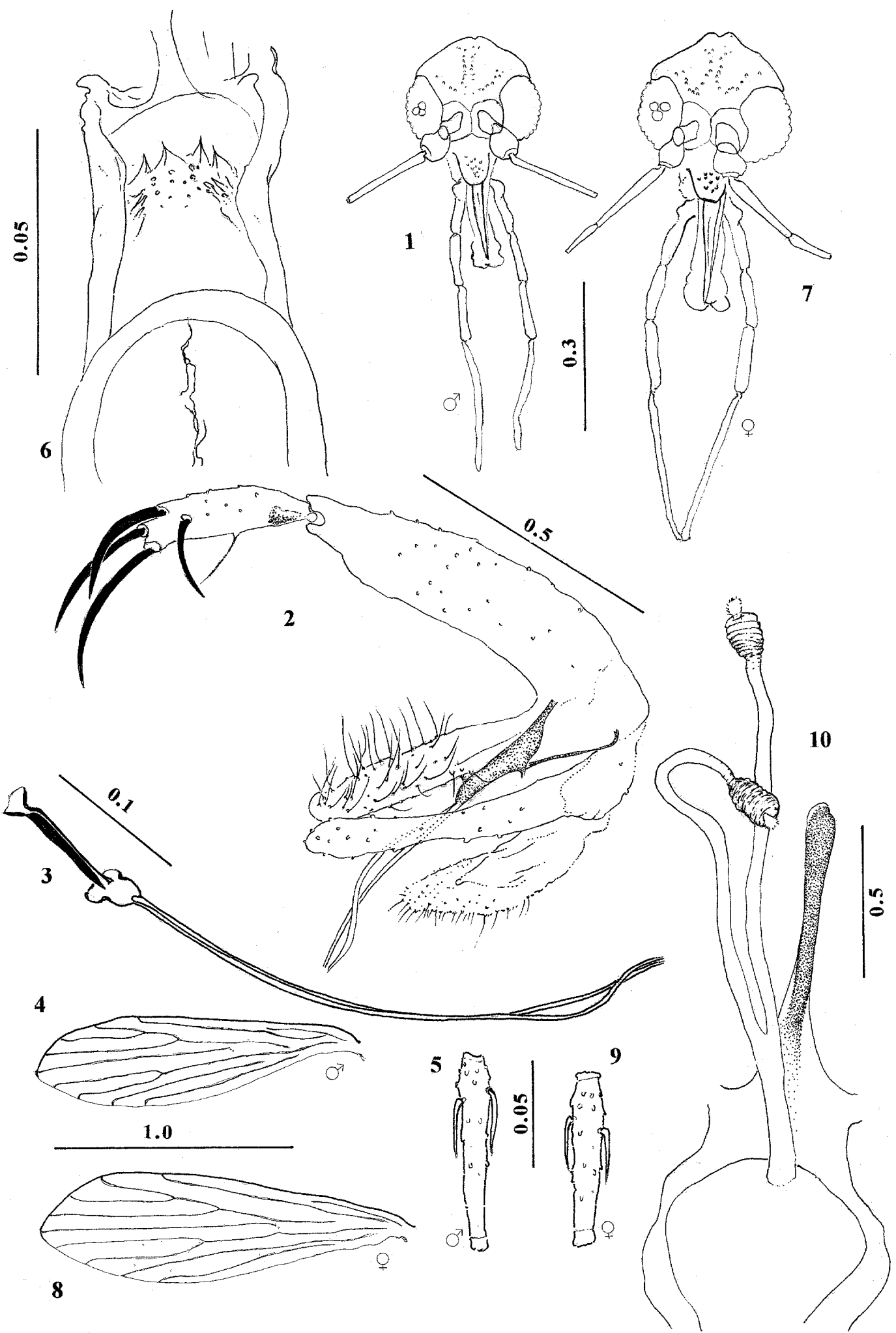

Lutzomyia derelicta Freitas \& Barrett, n. sp. Figs 1-5: holotype male. Figs 6-10: allotype female. Fig. 1: head. Fig. 2: terminalia. Fig. 3: genital pump and filaments. Fig. 4: wing. Fig. 5: flagellomere II. Fig. 6: cibarium. Fig. 7: head. Fig. 8: wing. Fig. 9: flagellomere II. Fig. 10: spermathecae, sperm ducts and genital fork. 
synapomorphy present in Lutzomyia and Brumptomyia and absent in the genera of Old World phlebotomines. Lewis et al. (1977) later referred to the presence of this structure in Phlebotomus (Australophlebotomus) brevifilis Tonnoir from Australia, but we are unaware of any previous report of a Lutzomyia species in which it is lacking.

In Lutzomyia the interocular suture is usually incomplete. Exceptions include a male of $L$. (Helcocyrtomyia) erwindonaldoi (Ortiz) illustrated by Young and Morales (1987) and both sexes of $L$. (Lutzomyia) evangelistai Martins \& Fraiha. In specimens of the latter species examined, the interocular suture is in fact stronger than in L. derelicta. In Sergentomyia this structure may be complete or incomplete (Lewis et al. 1977). Hairs on abdominal tergites 2-6 are usually all recumbent in Sergentomyia, but in the subgenus Sintonius a few erect setae are present on the posterior margins (Lane 1993). In the New World, recumbent scales are present on the tergites of at least some Lutzomyia (Psychodopygus) species, e.g. L. douradoi Freitas \& Fé. Two groups of mesanespiternal setae are usually present in Lutzomyia and absent in Sergentomyia, but in the Old World the subgenus Grassomyia is an exception (Rispail \& Léger 1998b).

Among the Old World phlebotomines, L. derelicta is closest morphologically to the species of the subgenus Sintonius of Sergentomyia according to the characters used by Rispail and Léger (1998b) for numerical taxonomy, differing on only four of the 19 applicable characters. Other character states that help to distinguish $L$. derelicta from Sintonius species with which it might be placed (cf Abonnenc 1972) are the absence of femoral spines and the relatively wide separation of the proximal spines of the style in the male. Where $L$. derelicta differs from Sintonius, on the ascoids of the male, the mesanepisternal setae, the tergite hairs and the apex of the male parameres, the state in $L$. derelicta could reasonably be regarded as the pleisiomorphic one.

Among New World phlebotomines, the females of $L$. derelicta have spermathecae resembling some species of the Verrucarum group but the latter species have the cibarial bulge normal for Lutzomyia. Males of $L$. derelicta are the only American phlebotomines with the style bearing four major spines of which two are terminal and a small proximal seta, all inserted individually; with the coxite lacking a discrete tuft of setae. Lutzomyia oligodonta Young, Pérez \& Romero 1985 from the Rimac Valley in Peru has an almost complete interocular suture, ascoids on the penultimate flagellomere, and a reduced proximal spine on the style, but in that species the median spines of the style are inserted on a common process.

Speculations on the evolution and historical biogeography of Phlebotominae, such as those of Theodor (1965 p. 179-180), Noyes (1998), or our view of $L$. derelicta as a possible pleisiomorphic vicariant of African Sergentomyia species, as well as more rigorously critical appraisals (eg Hennig 1972, Williams 1993) require a theoretical foundation. The renewed interest in the classification of Phlebotominae on morphological characters can contribute to this (Galati 1995, Rispail \& Léger 1998a, b) but analyses of molecular data will probably help to resolve both taxonomy and phylogeny less ambiguously than has been possible by morphology alone. We suggest that inclusion of $L$. derelicta in such analyses would be of particular interest.

\section{ACKNOWLEDGEMENTS}

To Artêmio Coêlho da Silva for the figures. To Dr João Carlos Henriques and his team at Mineração Rio do Norte SA for logistic support in Porto Trombetas. To Mr Laureano Viana for safely negotiating the rapids. To Dr Laurence Quate for specimens of Old World Phlebotominae.

\section{REFERENCES}

Abonnenc E 1972. Les Phlébotomes de la Région Éthiopienne (Diptera, Psychodidae). Memóires ORSTOM 55, Paris, 289 pp.

Ashford RW 1991. A new morphological character to distinguish Sergentomyia and Phlebotomus. Parassitologia 33 (Suppl. 1): 79-83.

Galati BEA 1995. Phylogenetic systematics of Phlebotominae (Diptera, Psychodidae) with emphasis on American groups. Bol Dir Malariol y San Amb 35 (Supl. 1): 133-142.

Hennig W 1972. Insektenfossilien aus der unteren Kreide IV. Psychodidae (Phlebotominae), mit einer kritischer Übersicht über das phylogenetische System der Familie und die bisher beschreibenen Fossilien (Diptera). Stuttgarter Beiträge zur Naturkunde 241: 1-69.

Lane RP 1993. Sandflies (Phlebotominae), p. 78-119. In RP Lane \& RW Crosskey (eds), Medical Insects and Arachnids, Chapman \& Hall, London.

Lewis DJ, Young DG, Fairchild GB, Minter DM 1977. Proposals for a stable classification of the phlebotomine sandflies (Diptera: Psychodidae). Syst Ent 2: 319-332.

Loczy L 1966. Contribuições à Paleogeografia e História do Desenvolvimento Geológico da Bacia do Amazonas, Departamento Nacional da Produção Mineral, Divisão de Geologia e Mineralogia (Boletim 223), Rio de Janeiro, 96 pp.

Noyes H 1998. Implications of a Neotropical origin of the genus Leishmania. Mem Inst Oswaldo Cruz 93: 657-661.

Pereira E, Martinelli G 1982. Novas espécies de 
Bromeliaceae do Brasil: 19. Bradea. Boletim do Herbário Bradeanum 3: 251-260.

Rispail P, Léger N 1998a. Numerical taxonomy of Old World Phlebotominae (Diptera: Psychodidae). I. Considerations of morphological characters in the genus Phlebotomus Rondani \& Berté 1840. Mem Inst Oswaldo Cruz 93: 773-785.

Rispail P, Léger N 1998b. Numerical taxonomy of Old World Phlebotominae (Diptera: Psychodidae). 2. Restatement of classification upon subgeneric morphological characters. Mem Inst Oswaldo Cruz 93: 787-793.

Theodor O 1965. On the classification of American Phlebotominae. J Med Ent 2: 171-197.

Williams P 1993. Relationships of the Phlebotomine sand flies (Diptera). Mem Inst Oswaldo Cruz 88: 177183.

Young DG, Duncan MA 1994. Guide to the Identification and Geographical Distribution of Lutzomyia Sand Flies in Mexico, The West Indies, Central and South America (Diptera: Psychodidae). Memoirs of the American Entomological Institute, No. 54, Associated Publishers, Gainesville, Fl., 881 pp.

Young DG, Morales A 1987. New species and records of phlebotomine sand flies from Colombia (Diptera: Psychodidae). J Med Ent 24: 651-665.

Young DG, Pérez JE, Romero G 1985. New records of phlebotomine sand flies from Peru with a description of Lutzomyia oligodonta, n. sp. from the Rimac Valley (Diptera: Psychodidae). Int J Ent 27: 136-146. 
634 Lutzomyia derelicta • RA Freitas, TV Barrett 